\title{
IMPLEMENTACIÓN SEMIPROFESIONAL DE CIRCUITOS IMPRESOS III
}

\section{IMPLEMENTATION SEMI PRINTED CIRCUIT III}

Arturo Pérez París: Universidad de Alcalá de Henares. Madrid (España) arturo.perez@mixmail.com

\section{CURRÍCULUM VITAE}

Escuela Politécnica de la Universidad de Alcalá de Henares. Ingeniero electrónico y literato. Destacan sus estudios sobre aplicaciones eléctricas y motricidad sobre los que ha publicado varios artículos científicos.

\section{RESUMEN}

La implementación semiprofesional de circuitos impresos permite la construcción de sus propios equipos y aplicaciones electrónicas. Por ello, este artículo va destinado principalmente a los estudiantes de ingenierías y bachilleratos técnicos. En él podrás seguir, paso a paso, la elaboración de estos circuitos con figuras explicativas en imágenes que reflejan con claridad la explicación dada por el texto, en la que además encontrarás variados consejos. La génesis de este artículo es parte del proyecto final de carrera de su autor, "Control digital de una montura ecuatorial para microcámaras". 


\section{PALABRAS CLAVE}

Circuitos impresos - Aplicaciones electrónicas - Estudiantes

\section{ABSTRACT}

Implementation semi printed circuit allows the construction of their own equipment and electronic applications. Therefore, this article is intended mainly for students of engineering and technical high schools. There you can follow step by step, the development of these circuits with explanatory figures in images that clearly reflect the explanation given by the text, which will also find various tips. The genesis of this paper is part of the final thesis of the author, "Digital control of an equatorial mount for micro cameras."

\section{KEY WORDS (u otro idioma hasta 5)}

Printed circuit boards - Electronic Applications - Students

\section{TEXTO:}

Ésta es la tercera (y última) entrega sobre este pequeño preámbulo a la implementación semiprofesional de circuitos impresos, con la finalidad de construir nuestros propios equipos y aplicaciones electrónicas, orientado fundamentalmente a todos los estudiantes de ingenierías y bachilleratos técnicos (antiguas F.P.) que precisen de ello (Industriales, Telecomunicaciones, etc.). Aquí trataremos los cuatro últimos pasos a dar, ya no sólo para la obtención de las PCBs, sino para la realización de un equipo totalmente acabado. 
$11^{\circ}$.- En este punto, empezaremos las primeras pruebas de las placas implementadas, comprobando si (eléctricamente hablando) responden como debieran. Es aquí donde también se realizarán los primeros ajustes, comprobando que la disipación calorífica de los componentes es la adecuada, que los consumos en los diferentes módulos es el correcto, que los niveles de tensión son los que deben ser y no otros, etc.:

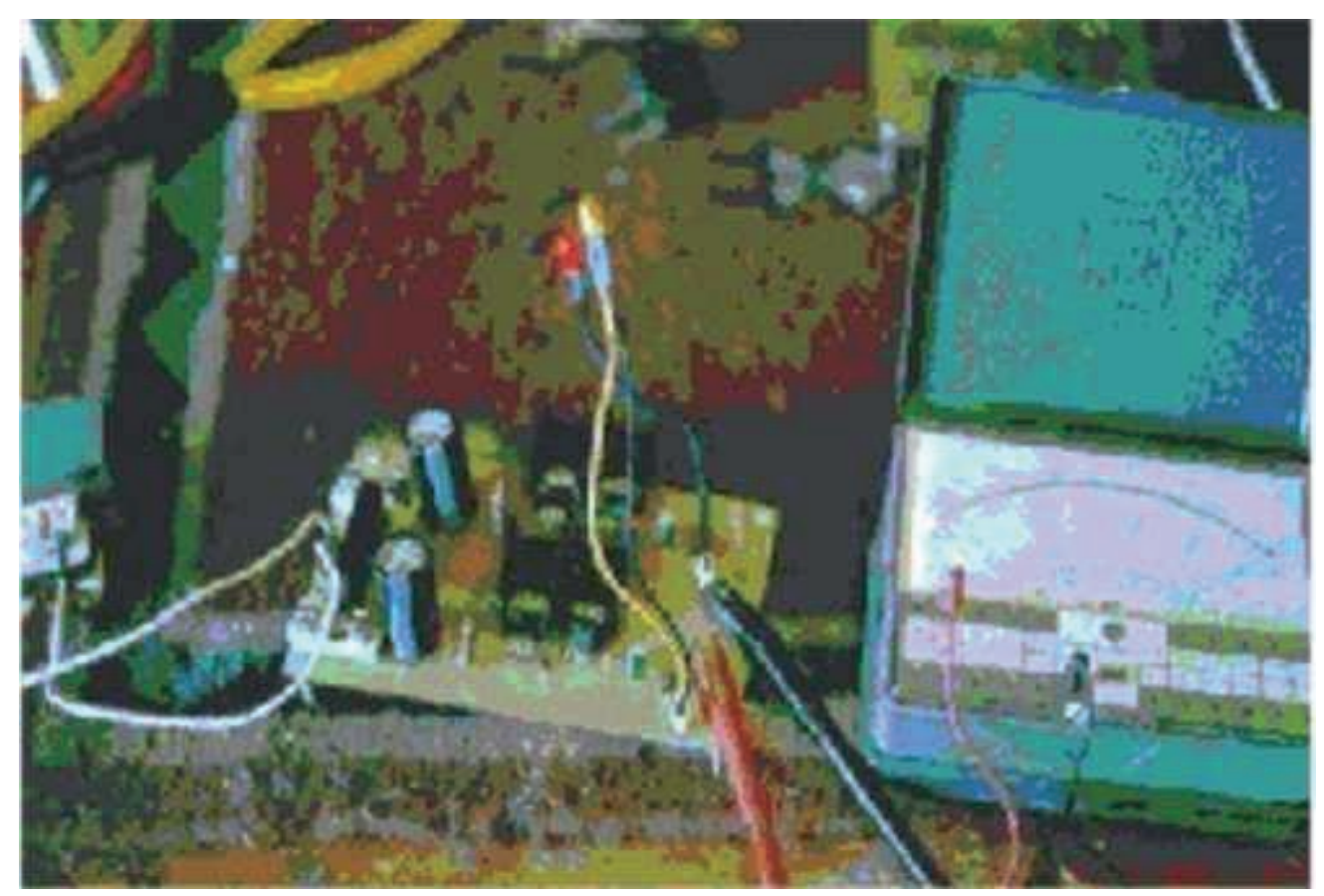

Fig. 18 a

En la imagen anterior se muestra el primer elemento a verificar: la fuente de alimentación del equipo. Esta comprobación empezará midiendo sus valores de salida en vacío (sin conectar al resto del equipo) evitando así dañar las demás secciones del sistema, si nuestra fuente no funciona como es debido. A continuación, con una fuente de alimentación de laboratorio, verificaremos el resto de las placas midiendo sus consumos y analizando si trabajan como es debido. Si todo está en orden, procederemos a conectar nuestra fuente de alimentación con el sistema, momento crítico en el cual veremos si todo el conjunto funciona, tal y como estaba previsto y se muestra en la siguiente fotografía: 


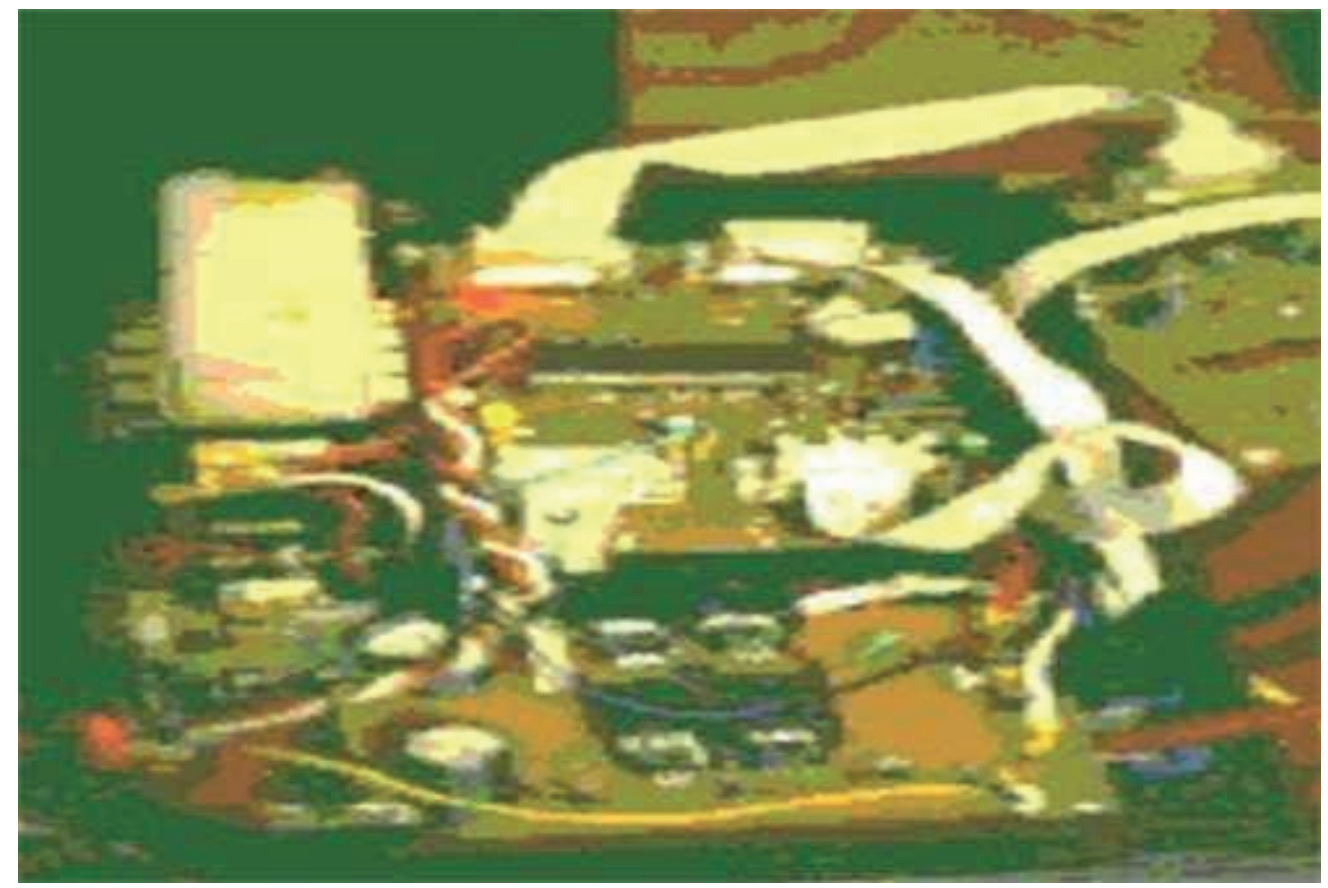

Fig. 18 b

$12^{\circ}$.- En esta fase se deberán buscar las cajas más adecuadas para nuestros circuitos, teniendo en cuenta las modificaciones a realizar en ellas para adecuarlas a nuestro equipo, esto es, que sean de sencilla mecanización. También se tendrá en cuenta el diseño que se quiere presentar, por lo que, a veces, se deberá recurrir a la pintura (recomendable en "spray") para cambiar el aspecto final del equipo. De esta manera, partiendo, por ejemplo, de las siguientes configuraciones:

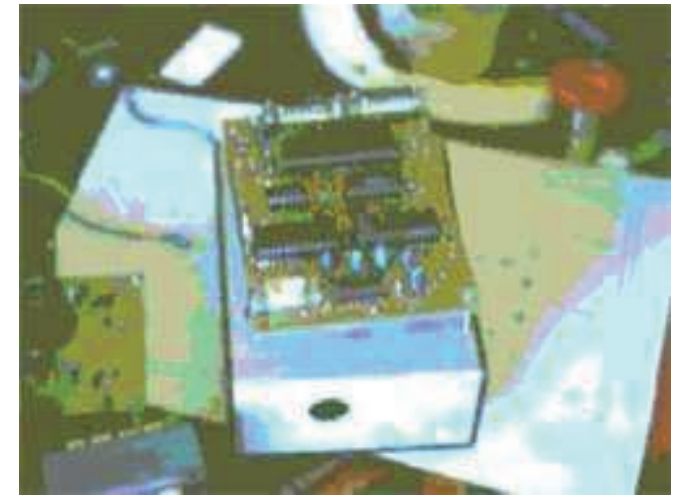

Fig. 19 a

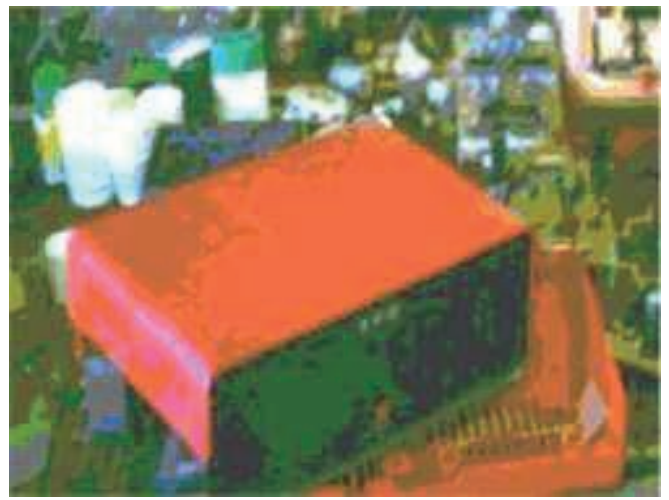

Fig. 19 b 
con algo de imaginación y "maña" se podrá obtener:

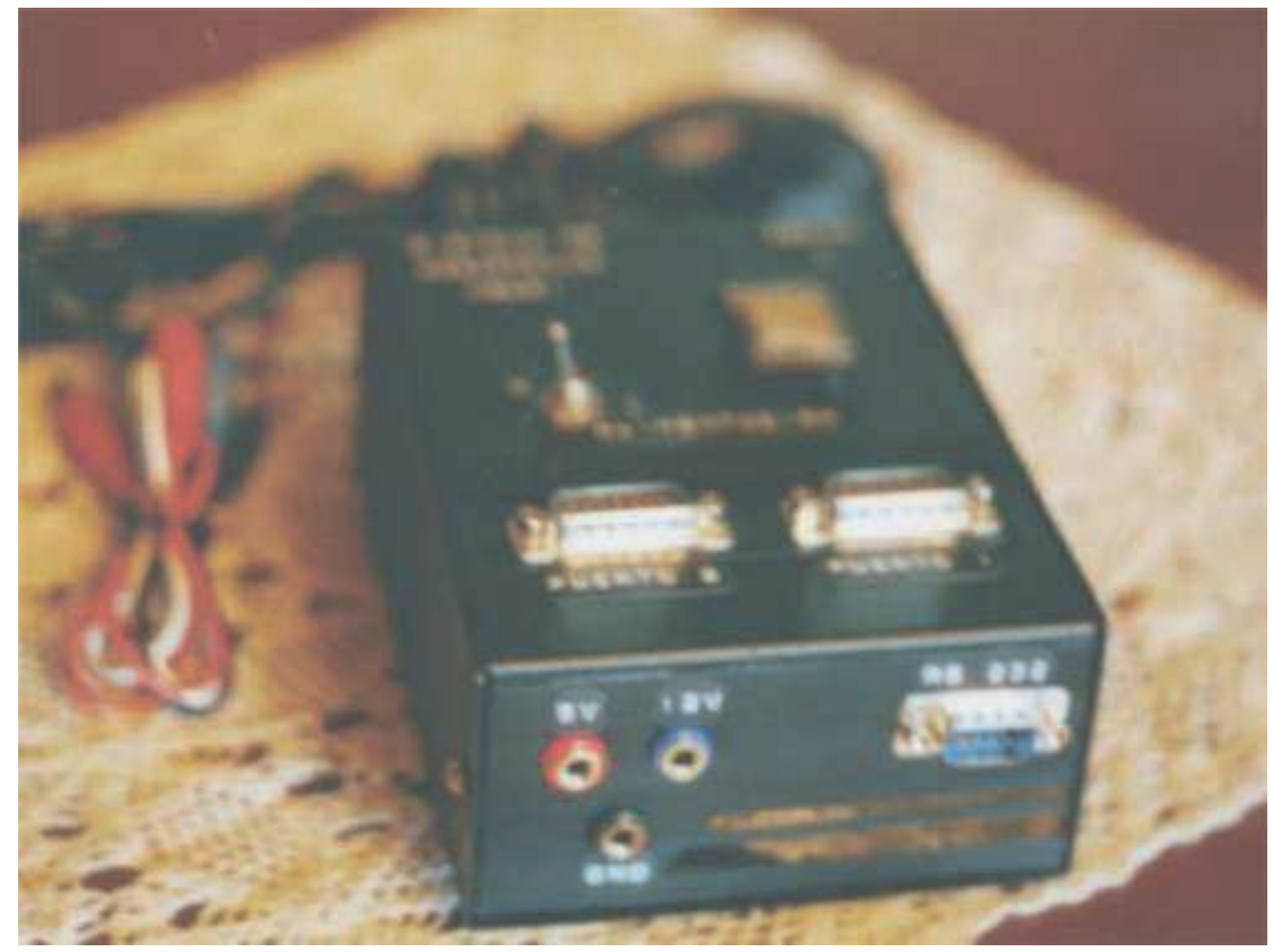

Fig. 20 a

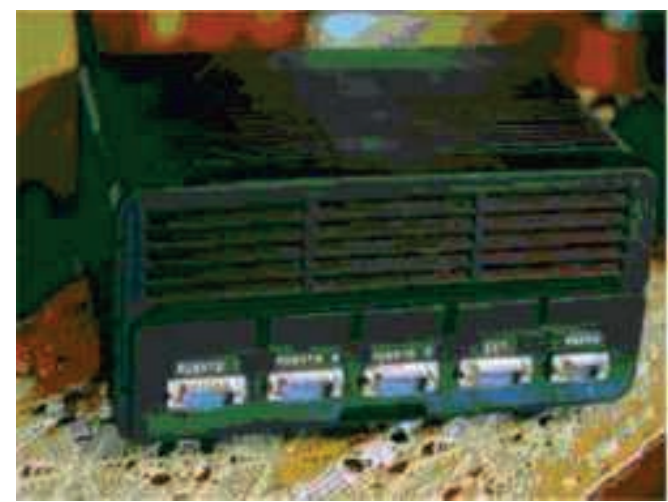

Fig. $20 \mathrm{~b}$

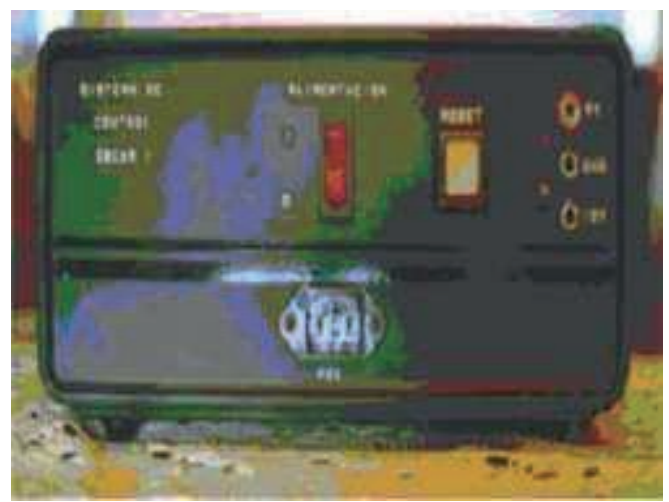

Fig. $20 \mathrm{c}$

Quizás sea ésta la etapa en la que más creativo debemos mostrarnos, ya que se desarrollará no sólo pericia, sino imaginación en la creación de diseños atractivos y funcionales. 
$13^{\circ}$.- Posteriormente se pasará a la creación de los programas y las filosofías de trabajo del equipo para la aplicación a la que se oriente.

$14^{1 \circ}$.- Por último, se procederá a una optimización y pulido de defectos de los módulos de forma individual, para después, de manera global, extender el proceso a todo el sistema, con el fin de presentar un producto final medianamente depurado y con el mínimo de posibles errores.

Damos por terminada la tercera y última entrega de este pequeño recetario de cómo fabricarnos nuestras propias placas de circuito impreso, cuya génesis parte de mi proyecto final de carrera: "Control digital de una montura ecuatorial para microcámaras" para el Dpto. de Teoría de la Comunicación, E. Politécnica de la Universidad de Alcalá. 